\title{
Spontaneous Interaction on Context-Aware Public Display: An NFC and Infrared Sensor approach
}

\author{
Gabriel Chavira, Salvador Nava \\ Faculty of Engineering \\ Autonomous University of Tamaulipas \\ Tampico, México \\ \{gchavira, snava\} @ uat.edu.mx
}

\author{
Ramón Hervás, José Bravo \\ MAml Research Group \\ Castilla-La Mancha University \\ Ciudad Real, Spain
}

\{ramon.hlucas, jose.bravo \}@uclm.es

\author{
Carlos Sánchez \\ CCNT-Spain \\ carlos.barba@ccnt-spain.com
}

\begin{abstract}
Public Display offers an excellent conduit for automatic delivery of information in an intelligent environment that is tailored to the user. We have detected some situations in which some kind of interaction with public displays is needed. The objective should require minimum interactive effort on the part of the user. In this work we present our experience when we tested two forms of interacting with public displays: Infrared sensors, to detect a sweep of the hand over the sensor; and a Near Field Communication (NFC) enabled cell phone, which used a mobile keyboard to carry out the interaction.
\end{abstract}

\section{Categories and Subject Descriptors}

H.5.2 [Information Systems]: User Interfaces - Input devices and strategies, Interaction styles.

\section{General Terms}

Human Factors

\section{Keywords}

Keywords: Public display, NFC, Interaction.

\section{INTRODUCTION}

AmI is a vision that promotes environments where humans will be surrounded by intelligent interfaces, supported by computing and networking technology that is embedded in everyday objects. These will adapt to the needs of users and will be capable of responding intelligently to any human form of communication. [1]. This is an evolution from Ubiquitous Computing, a vision originating in Mark Weiser [2],where computers disappear and are embedded into the background. Weiser's vision also has to do with: Ubiquitous Communication, which is between object and users and whose main goal is to get the information at the time and place that users need; and Natural Interfaces, which make the interaction friendlier and closer to the user.

In an intelligent environment the user (any person within the environment with AmI) can receive services implicitly, or with minimum interactive effort. Context awareness is an essential

Permission to make digital or hard copies of all or part of this work for personal or classroom use is granted without fee provided that copies are not made or distributed for profit or commercial advantage and that copies bear this notice and the full citation on the first page. To copy otherwise, to republish, to post on servers or to redistribute to lists, requires prior specific permission and/or a fee. IMMERSCOM 2007, October 10-12, Verona, Italy

Copyright (c) 2007 978-963-9799-06-6

DOI 10.4108/ICST.IMMERSCOM2007.2253 characteristic for offering implicit services to users. Anind Dey defines a context-aware system as "that system that uses context to provide relevant information and/or services to the user, where relevancy depends on the user's task” [3].

Giving information to the user is fundamental in an intelligent environment. Public displays offer an excellent conduit for automatic delivery of information that is tailored to the user or to access our information. Many researchers have already been tackling different issues related to displays in AmI, such as: privacy, sharing, ways to represent information, interacting with the display, etc.

Interacting with the public display has to be done in some situations. We can use a wide range of equipment to interact with a public display: keyboard and mouse or gyroscopic mouse, speech, video/gesture recognition, motion tracking or specific development devices. The ideal interactions would be those that are natural to the user, without any equipment being required, but at the moment this is unaffordable. Vogel and Balakrishnan propose implicit access to public information and explicit access to personal or private information [4].

In previous works [5] [6] we used RFID (Radiofrequency Identification) technology for visualization services by display in an intelligent environment and recently we began to explore the use of Near Field Communication (NFC) in an intelligent environment for obtaining services at a point.

In this work we present two forms of interacting with public displays: Infrared sensor and the NFC- enabled cell phone. The first is economical and only requires a slight movement of the hands. The latter uses the device of most widespread use at the present time.

\section{RELATED WORK}

Like other researchers, we are investigating devices which interact with public displays, with the idea of integrating them into intelligent environments. In this section we describe other work that is relevant for our research.

The Universal Interaction Controller (UIC), of Slay and Thomas [7]; includes Ukey, a pocket pc with a motion sensor $20 \mathrm{~cm}$. from the top of device. The user uses this to point at a display in order to select it and thus can manipulate data across multiple heterogeneous displays for selecting, copying and pasting, etc.

Vogel and Balakrishnan, [4] using touch sensitive overlay, support up-close interaction using fingers. A motion tracking system provides high resolution location and orientation data for the user's head, body, right hand and selected fingers. 
WorldCursor [8] is a pointing device and cursor designed for intelligent environments. It can be used to interact with a physical device by just positioning the cursor on the device and clicking, requiring no additional equipment such as positional technology or video cameras.

HoloWall [9] is a wall-sized computer display that allows users to interact without any special pointing devices. To recognize inputs using: a glass wall (as display), a video projector behind the wall which displays images on the glass wall, and a system for recognizing inputs, which is formed by: infrared lights and a video camera with an infrared light filter (an optical filter that blocks light below $840 \mathrm{~nm}$ ) installed behind the wall.

SmartSkin [10] make interactive surfaces that are sensitive to human hand and finger gestures. They use a mesh of transmitter/receiver electrodes (such as copper wires) to build a layer on the surface. This makes it possible for the interactive surface to be large, thin, or even flexible.

Blueboard, developed by IBM, uses a display and RFID technology in collaboration with users [11]. Meme Tags propose the use of RFID technology to support the collaboration of tagwearing users [12]. The IntelliBadge project also aims to facilitate services to those attending academic conferences, tracking people by RFID tags and showing them information on different displays [13].

\section{ViMos: VISUALIZATION MOSAIC}

We are using ViMos (Visualization Mosaic) to offer adapted information to the user through displays placed in the environment, thus tailoring information through context awareness.

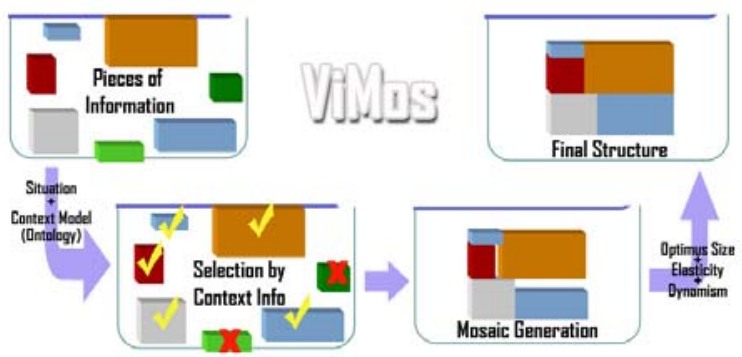

Figure 1. Generation process of a mosaic.

A mosaic of information is a set of information pieces that form a user interface. Initially we have a whole set of information pieces. A matching between the situation and the context model makes possible the selection of the best pieces. Each piece has several associated characteristic (e.g. Optimum size, elasticity, etc.). These characteristics make possible the final generation process of the mosaic (Figure 1).

A mosaic is formed by "blocks" of information. Each block is considered as ato be a piece of a puzzle. The relevance of each block is set by the context model. ViMos defines a model in which the complex real world is abstracted. As a result, computational systems may understand the world around them and act accordingly (similar to human behavior). For this reason, a key issue of ViMos is a formal ontology as a context model. In [14] the model is described thoroughly.

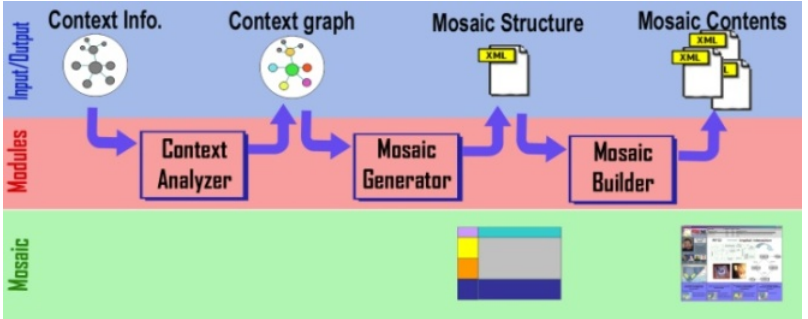

Figure 2. ViMos modular architecture.

A mosaic is configured by joining the best pieces; this concept illustrates several important characteristics of ViMos, namely, Dynamism, Adaptability and Quality of the contents offered.

The scenarios where ViMos can be used have the use of public displays as a common feature. In our research, we develop a prototype in an education context. The key places are: the traditional classroom and the research laboratory. Another context studied is the academic conference and we are exploring hospital scenarios at present.

The ViMos architecture is made up of three modules: Context analyzer, Mosaic generator and Mosaic Builder; as is displayed in Figure 2.

The fact that people are continuously entering and leaving a classroom makes this an excellent place for using ViMos.

In figure 2 the architecture of ViMos in the classroom can be observed. We installed a ViMos server and RFID equipment (readers and antennas) in this space and both teachers and student have to wear tags there. With these tags, the location (attendance) and access control services are activated automatically.

The blocks in the mosaic change according to: the Lecturer, the Students, the Schedule, the class interaction and the questions. An example of ViMos screen in this scenario can be seen in Figure 3.

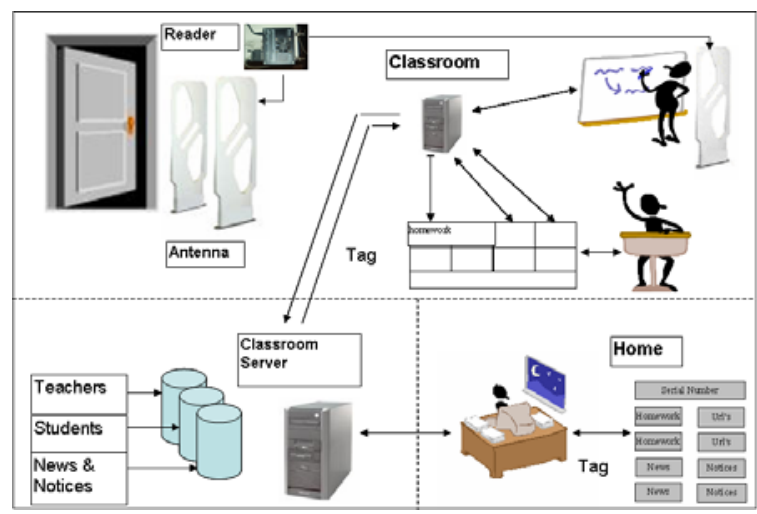

Figure 3. Architecture for the classroom

During the actual class-time, the mosaic is changed and it presents information prepared by the lecturer for the session in hand. In the time between classes, ViMos displays news and announcements for the students present.

ViMos can distinguish between who (student or lecturer) is standing in front of the display. When it is the lecturer who approaches the board, his lesson presentation, the problems proposed, their solutions, his documentation, etc. are shown. If it is a student, the display shows: information, questions, and any 
other digital contribution prepared by the student before class time.

An example of the situation when the lecturer comes into the classroom is shown in Figure 4. In the illustration, we can observe different parts of the board, showing information about attendance (1), the lecturer's plan (2) for controlling the order of these activities, plan of the building/floor (3), schedule (4), lesson presentation (5) and documents (6 \& 7).

To solve possible conflicts when more than one person is in front of the display, ViMos has an "audience control". Using this, the lecturer may authorize some student to take control of the display or, on the other hand, he or she may deny that authorization.

ViMos is complemented by "work at home"; this is really work done outside the classroom. In this application, the student has a contact reader so he can put his contribution to the class (the problem solved, doubts, etc.) in his tag.

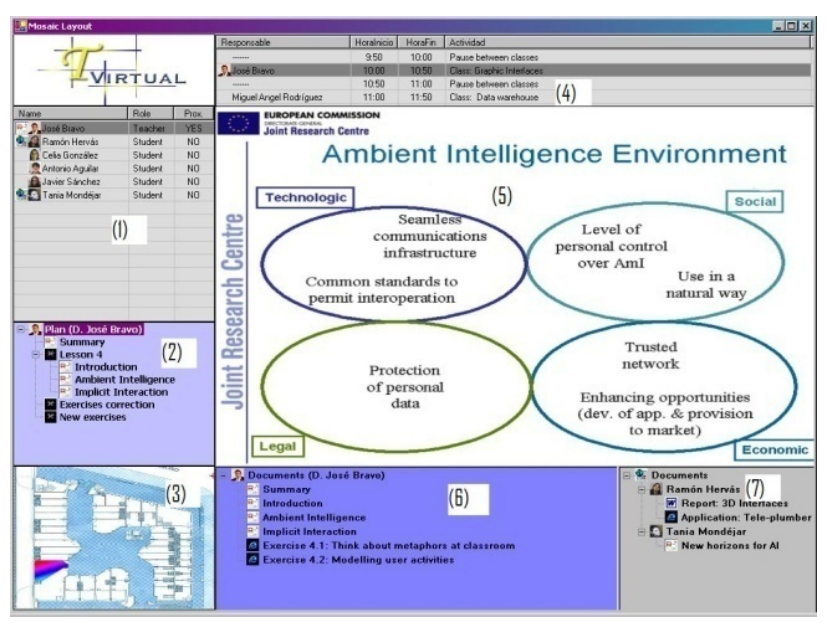

Figure 4. Mosaic of Information

\section{ViMos: EXPLICIT INTERACTION}

We have detected some situations in which some kinds of interaction are needed. In these, managing the information display is important and to that end we encourage the use of simple devices. We decided to test two options: Infrared sensors and NFC-enabled cell phone. In the following sections we explain our experiences with both.

\subsection{Infrared sensors}

The first option was implemented by integrating two or four infrared sensors (Basic X24 Micro-controller that transmits through Bluetooth). The options of whether there are two or four sensors are chosen according to the quantity of interactive actions that are required for each situation. In the case of a conference, two are enough. By just a sweep of a hand over the sensor, this indicates to the system that the user wants to advance or to go back in the pages of a presentation.

The user could change the action that each sensor will make, according to the situation and user preferences (see Table 1).
Table 1. Sensor functionalities

\begin{tabular}{|l|l|l|l|}
\hline User Profile & \multicolumn{1}{|c|}{$\begin{array}{c}\text { Additional } \\
\text { Contextual } \\
\text { Information }\end{array}$} & \multicolumn{1}{|c|}{$\begin{array}{c}\text { Sensor } \\
1\end{array}$} & $\begin{array}{c}\text { Sensor } \\
2\end{array}$ \\
\hline Teacher & Schedule & $\begin{array}{l}\text { Select student } \\
\text { group }\end{array}$ & $\begin{array}{l}\text { Activate group } \\
\text { presentation }\end{array}$ \\
\hline Student 1 & $\begin{array}{l}\text { Schedule } \\
\text { Teacher } \\
\text { activation }\end{array}$ & Previous slide & Next Slide \\
\hline Student 2 & Final Slide & Previous slide & $\begin{array}{l}\text { Restart } \\
\text { presentation }\end{array}$ \\
\hline
\end{tabular}

Figure 5 shows a ViMos in a real experience with students of the Education Faculty of Castilla La Mancha University (Spain). In a classroom scenario four sensors are needed to control all interaction situations between lecturer and students. The functionality of each sensor is adapted to the user, according to their needs, in each mosaic.
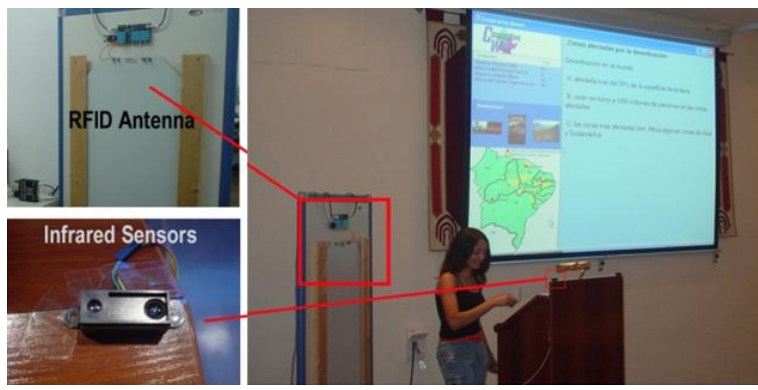

Figure 5. RFID and infrared sensors

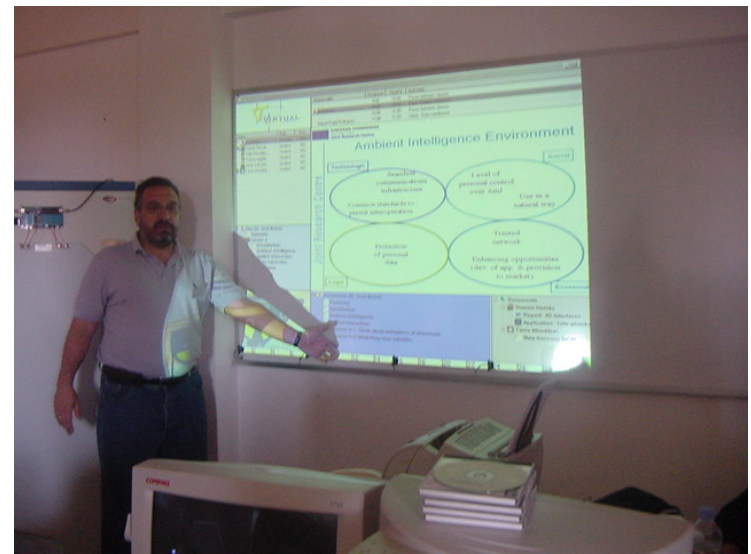

Figure 6. Use of four sensors in a classroom scenario.

In Table 2 an example of the adapted functionality can be seen. Figure 6 show four sensors in a classroom scenario.

Table 2. Example of sensor functionality

\begin{tabular}{|c|c|c|c|c|}
\hline Profile & Sensor 1 & Sensor 2 & Sensor 3 & Sensor 4 \\
\hline Teacher & $\begin{array}{l}\text { Begin } \\
\text { Session }\end{array}$ & $\begin{array}{l}\text { Next } \\
\text { Student }\end{array}$ & $\begin{array}{l}\text { Previous } \\
\text { Student }\end{array}$ & End Session \\
\hline Student & $\begin{array}{l}\text { Next } \\
\text { Slide }\end{array}$ & $\begin{array}{l}\text { Previous } \\
\text { Slide }\end{array}$ & $\begin{array}{l}\text { Interac- } \\
\text { tion with } \\
\text { contents }\end{array}$ & $\begin{array}{l}\text { Back to the } \\
\text { break slide }\end{array}$ \\
\hline
\end{tabular}

\subsection{NFC}

Despite the low cost of infrared, it has one drawback, which is that infrared devices must be added to all the displays in the 
intelligent environment. This is hardly practical when the amount of displays is considerable. The use of the infrared sensor is advantageous only when the number of displays is small.

A cell phone is a very popular device and in some countries the number of cell phones is greater than the total population figure. The current cell phone has a series of features: Camera, Bluetooth, Voice Record, Mp3, TV, etc. Near Field Communication (NFC) is an open protocol development by Sony and Philips and is a short range wireless connectivity technology combining RFID and interconnection technologies.

It was developed to be compatible with RFID tags that work in the high frequency band of up to $13.56 \mathrm{MHz}$ (ISO 14443), but is incompatible with the EPC global standard. Basically, two NFCenabled devices are required and, among the advantages of these devices, we see that any of them can act as:

- Initiator. This begins and controls the information exchange ( in RFID terminology we would call this the reader)

- Target. This is the device that responds to the requirements of the initiator (we would call it the tag).

It is important to mention that, although the NFC protocol can be installed in any electronic device, our interest will focus on NFCenabled cell phones at the present time. NFC-enabled TV does not exist commercially yet.

By just bringing two NFC-enabled devices near to each other, that is enough to establish the communication between them.

To explore the use of the NFC-enabled cell phone in interacting with a public display it was necessary to place in it:

- Target. To recognize which display will use and establish communication with it through

- Bluetooth

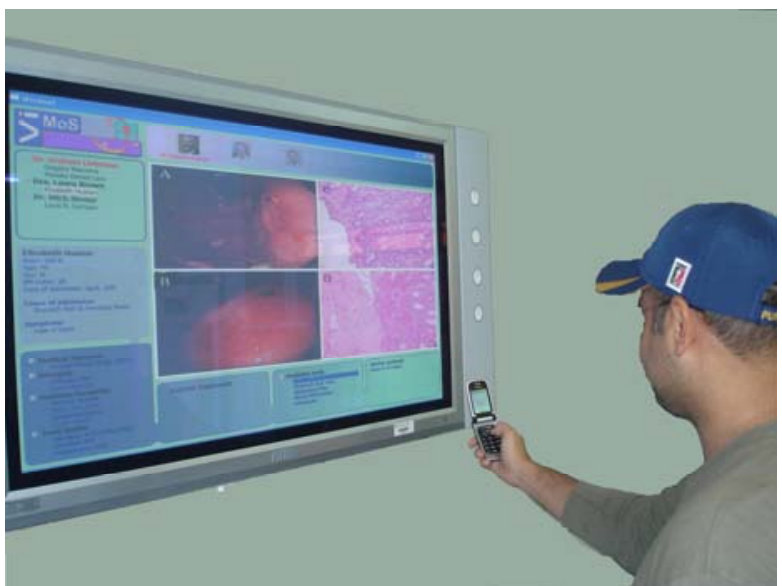

Figure 7. NFC-enabled cell phone interacting with a public display.

When the user is in front of a display with which he wants to interact, he will bring his cell phone near the display and, by setting up NFC communication, the application in the cell phone recognizes that an interaction with the public display is required executing the module that carries out this function. At this point, the keys of the cell phone will allow the information displayed to be manipulated. This is shown in figure 7.

\section{CONCLUSION AND FUTURE WORK}

Public displays for delivering information tailored to the user are of capital importance in an AmI scenario. Sensing technology such as RFID allows there to be a perceiving of the user, thus creating context awareness. But the user is not satisfied with just looking at information. He needs to be able to manipulate it.

Applications with this capacity already exist but they are still devices at the development stage, needing large investment and they are not very practical or feasible. We propose two different options to offer to the user for interacting with a public display: Infrared sensors and the NFC enabled Cell phone. The first is a valid choice in certain cases where the quantity of displays is small. We believe the second one is the best option for the future.

The NFC enabled cell phone means that the user does not need to have another device which he has to learn how to handle. The NFC enabled cell phone is perfect for interaction with not only a public display, but with any other device in AmI: that is precisely one of the goals in our research.

\section{REFERENCES}

[1] Information Society Technologies Advisory Group ISTag, Ambient Intelligence: from vision to reality. 2003, European Commission. p. 31.

[2] Weiser, M., The Computer for the 21st. Century. Scientific American, 1991. 265(3): p. 94-104.

[3] Dey, A.K., Understanding and Using Context. Personal and Ubiquitous Computing Journal, 2001. 5(1): p. 4-7.

[4] Vogel, D. and R. Balakrishnan. Interactive Public Ambient Display: Transitioning from Implicit to Explicit, Public to Personal, Interaction whith Multiple Users. in 17th ACM Symposium on User Interface Software and Technology (UIST'04). 2004. Santa Fe, New Mexico, USA.

[5] Bravo, J., et al., Visualization Services in a Conference Context: An approach by RFID Technology. Special issue of Ubiquitous Computing and Ambient Intelligence. Journal of Universal Computer Science, 2006.

[6] Bravo, J., R. Hervás, and G. Chavira, Ubiquitous computing at classroom: An approach through identification process. Journal of Universal Computer Science. Special Issue on Computer and Educations., 2005. 11(9): p. 1494-1504.

[7] Slay, H. and B.H. Thomas. Evaluation of a Universal Interaction and Control Device for use within Multiple Heterogeneous Display Ubiquitous Environments. in Seventh Australasian User Interface Conference (AUIC 2006). 2006. Hobart, Australia.

[8] Wilson, A. and H. Pham. Pointing in Intelligent Environments with the WorldCursor. in International Conference on Human-Computer Interaction (Interact '03). 2003. Zurich, Switzerland.

[9] Rekimoto, J., et al. HoloWall: interactive digital surfaces in International Conference on Computer Graphics and Interactive Techniques (SIGGRAPH 98). 1998. Orlando, Fl USA.

[10] Rekimoto, J. SmartSkin: An Infrastructure for Freehand Manipulations on Interactive Surfaces in Conference on 
Human Factors in Computing Systems (SIGCHI 2002). 2002. Minneapolis, Minnesota, USA

[11] Russell, D.M., J.P. Trimble, and A. Dieberger. The use patterns of large, interactive display surfaces: Case studies of media design and use for BlueBoard and MERBoard. in 37th Hawaii International Conference on System Sciences. 2004.

[12] Borovoy, R., et al. Meme tags and community mirrors: Moving from conferences to collaboration. in ACM Conference on Computer Supported Cooperative Work. 1998.
[13] Cox, D., V. Kindratenko, and D. Pointer. IntelliBadge: Towards Providing Location-Aware Value-Added Services at Academic Conferences. in Fifth International Conference on Ubiquitous Computing (Ubicom 2003). 2003.

[14] Hervás R, Bravo J, Chavira G, Nava S. Servicios de Visualización de Información Conscientes del Contexto: Modelo Semi-Formal y Escenarios (Spanish). In: Conferencia Ibérica de Sistemas y Tecnologías de la Informa-ción. Esposende. 2006. 